\title{
Knowledge on Preconception Care Among Reproductive Aged Women in Kaski District, Nepal
}

\author{
Krishma Giri* \\ Staff Nurse, Gandaki Medical College \\ Srijana Gautam \\ Lecturer, Gandaki Medical College, Pokhara, Nepal
}

Received July 15, 2018

Revised September, 2018

Accepted December, 2018

\begin{abstract}
Preconception care is any intervention provided to women and couples of childbearing age, regardless of pregnancy status or desire, before pregnancy, to improve health outcomes for women, newborns and children. The aim this study was to assess level of knowledge among reproductive aged women and to find out association between selected demographic variables and knowledge. A descriptive cross sectional research design was used to conduct the study. Non probability purposive sampling technique was used to select 220 reproductive aged women in Pokhara, Metropolitan city-32 ;Janachautra, Malmul. Data was collected through structured interview schedule and analyzed using SPSS version 16. Data was analyzed using descriptive and inferential statistics such as frequency, percentage, mean, standard deviation, Chi-square test. The findings revealed that about 20 percent of respondents possessed poor knowledge followed by 64.5 percent of the respondents possessed average level of knowledge and 15.5 percent of respondents possessed good level of knowledge. The

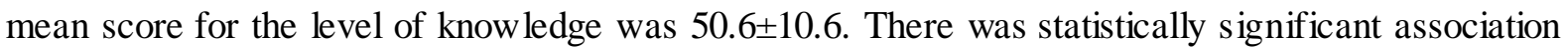
betweenlevel of knowledge on preconception care with education, number of children, heard about preconception care, source of information $(\mathrm{p}<0.005)$.Itconcludes that majority of the respondents had average level of knowledge so, awareness program is required to to prevent the health risks of women and offspring in the near future and to improve the different aspects of knowledge regarding preconception care.
\end{abstract}

Keywords: Education, know ledge, preconception care, reproductive aged women

(C) The Authors. Published by JRCC, Janapriya Multiple Campus

ISSN 2362-1516

* Corresponding author

Email: Krishma.giri.21@gmail.com

\section{Introduction}

Preconception care (PCC) is a relatively new conceptthat was first described by Chamberlain in 1980(Chamberlain, G. 2011).Preconception care is the provision of biomedical, behavioral and social health interventions to women and couples before conception occurs. It aims at 
improving their health status, and reducing behavior and individual and environmental factors that contribute to poor maternal health (Tuitui, R. 2016).Preconception care is the integral part of antenatal care as it helps to reduce potential risk, maternal \&child mortality, birth defect in infant like neural tube defect, low birth weight baby, preterm and post-term baby, as well as promote healthy pregnancy and fetal outcome and improve readiness for pregnancy (WHO, 2013).On 2012, the Inter-Agency group for Safe Motherhood developed a package of services which included various preconception care services such as family planning, adolescent reproductive health education services etc (Moos et al., 2009 ). The importance of preconception care has gained greater recognition with the World Health Organization (WHO) Global Action Plan for the Prevention and Control of Non-communicable Diseases 2013-2020 (Ojukwu et al., 2016) .

In 2010, globally 287000 women died suffering with the long term disability due to the cause related to pregnancy \& childbirth. During same year, globally 3.1 million newborn babies were expired in first month of life, while premature babies were 14.5 million $\& 2.7$ million were stillborn (Dean et al., 2014). Approximately four million global neonatal deaths that occur annually, 98 percent occur in developing countries, where most newborn die at home while they are cared by mothers, relatives and traditional birth attendants (WHO, 2011).Major causes of neonatal deaths worldwide are infections 36 percent which includes sepsis/pneumonia, tetanus and diarrhea, complication of prematurity 20 percent and birth asphyxia and injuries 29 percent, congenital anomalies 10 percent. Globally more than 20 million infant are born with low birth weight. The maternal death in the world is 5,36000. 960 in a developed region, 533,0001 in a developing region. The maternal mortality ratio is 281/100000 live birth and neonatal mortality rate is33/1000(Dhakal, 2013).

In 2006, an estimated 30 percent of U.S. women have complications during pregnancy. Currently, 12 percent of babies are born prematurely, 8 percent are born with low birth weight, and 3 percent have major birth defects (Kent et al., 2006). Studies have found that only 13.5 percent to 15.2 percent of women in Oklahoma receive preconception care. Only 12.0 percent of Oklahoma women received advice or counseling to prepare for becoming pregnant (PRAMS Working Group. 2010).

In Asia, in Kelantan, Malaysia, while assessing socio-demographic data and knowledge, attitudes and practice of preconception care the mean (SD) knowledge, attitude and practice scores were 11.37 (3.94), 15.39 (2.12) and 10.13 (2.30), respectively (Kasim et al., 2016). 
According to 2008/2009, 69 percent of maternal death are due to direct cause $\& 39$ percent maternal death are due to indirect cause. The number of neonatal death in Nepal is 24,261 in a year, 66 in a day \& 3 in an hour (Dhakal, 2013).In Nepal, while assessing Knowledge on preconception care among 55 reproductive age women visiting the Gynecologica/Obstetric OPD of National Medical College Teaching Hospital the majority 69.09 percent of reproductive age women had moderate knowledge regarding preconception care, 20 percent had inadequate knowledge and 10.91 percent had adequate knowledge (Thakuri\& Singh, 2017).

As this locality is in developing phase, the maternal mortality and infant mortality rate is high, many respondents were deprived of proper health education along with precautions regarding preconception care which signifies the importance of such research in my community.

The aim of this study was to assess the Knowledge on Preconception Care among the Reproductive Aged Women in Pokhara Metropolitan city- 32 :Janachautra, Malmul. In Nepal, preconception care is the new concept and the research done in this topic is limited. Nepalese population hasn't been explore to the preconception care concept so to generalize the concept the researcher felt the need to assess level of knowledge on .preconception care among reproductive age women.

\section{Data and Methods}

Among 32 wards of Pokhara Munic ipality one ward was selected by using simple random (Lottery) method .Pokhara- Lekhnath Metropolitan City-32, Janachautra, Malmulis chosen as the research area as this place is the intermediary between urban area and rural area. Urban area is developed with more opportunities for women educationand rural area lacks such provision. The study population was married reproductive aged women.List of total population of reproductive age women was collected from VDC office i.e. 3079. Each respondents was selected by purposively. Household were approached with the help of FCHV. If the inclusion criteria were not met, the next respondent was taken until required sample size was met. Thesample size was 220 according to prevalence rate $(15.42 \%)$ of article on knowledge on preconception among reproductive age women (Gautam, 2016).

Structured interview schedule was used to collect the information on the basis of objectives of the study.Self-developed, structured and pretested questionnaire were used to collect the information. The questionnaire consisted of two parts with includes31questions. Part 
Iincluded the items regarding socio demographic characteristics (age, religion, ethnicity, type of family, education,occupation, number of children, source of information) and Part 11 consists questionnaire regarding knowledge on preconception care (definition, necessary, components, advantage, importance, preconception counselling, barrier, laboratory investigation, timing for folic acid supplementation and its benefits ).

Tool was finalized on the basis of Objectives of the study. Content validity of the instrument was ascertained by consultation with colleagues, research advisors, faculties and subject experts. Pretesting of the tool was done in a locality which is similar in setting to assess the clarity, feasibility and appropriateness of instrument among 20 reproductive aged women (10\% of sample size) Rupa lake VDC, Nepal. Necessary modification was done after pretesting in order to ascertain the relevancy,consistency and completeness of instruments. Similarly, sentence structure was made more simplified after pretesting with the help of language expert.Since the respondents were homogenous, reliability has not been computed.

The study was carried out after the approval of research proposal from the Institutional Review Board (IRB), Novel Academy for ethical clearance.The ward secretary and ward chairman were briefed about the objectives, duration, times and process of data collection of study. The data was collected by the researcher herself from 2017-6-2 to 2017-6-29.In order to protect the right of respondents, informed consent (both verbal and written) was taken from each respondents before collecting data. Structured interview schedule was used to collect information by the researcher individually at time 11 an to $5 \mathrm{pm}$. The anonymity of the information was maintained by asking not to write their names in questionnaire. The participation in the study was voluntary and was free to withdrawn at any time of data collection. All the information obtained was treated with confidentiality and was used for the sole purpose of research.

After the completion of data collection,the data was checked thoroughly and organized for the completeness and consistency. The collected data was coded, entered, tabulated and analyzed using Statistical Package for Social Science (SPSS) version 16. Descriptive statistics (frequency, percentage, mean and standard deviation and range) was used to describe the characteristics of collected data and inferential statistical method (Chi-square test) was used to find association between two categorical variable. The level of significance was set as $5 \%$ with p value $<0.05$ and $95 \%$ confidence interval. Regarding knowled ge, each of the correct answer was given the weightage score 1. The mean score for level of 
knowledge was 50.6 \pm 10.6 . Total score was 73 which was converted into range $<40,40-61$, $>61$. On the basis of score range obtained by the respondents, knowledge level was categorized as 'poor' if the score was less than 40 and 'average' if the score ranges from 4061 then 'good' if score was greater than 61 .

\section{Results and Discussion}

Table 1

Respondents Classified According to Selected Background Characteristics $(n=220)$

\begin{tabular}{|c|c|c|}
\hline Characteristics & Frequency & Percentage \\
\hline \multicolumn{3}{|l|}{ Age (in years) } \\
\hline $15-20$ & 2 & 0.9 \\
\hline $21-25$ & 36 & 16.4 \\
\hline $26-30$ & 58 & 26.4 \\
\hline$>30$ & 124 & 56.4 \\
\hline \multicolumn{3}{|c|}{ Mean $\pm \mathrm{SD}==3.38 \pm 0.78$} \\
\hline \multicolumn{3}{|l|}{ Religion } \\
\hline Hindu & 188 & 85.5 \\
\hline Buddhist & 27 & 12.3 \\
\hline Christians & 5 & 2.3 \\
\hline \multicolumn{3}{|l|}{ Ethnicity } \\
\hline Brahmin & 104 & 47.3 \\
\hline Chhetri & 25 & 11.4 \\
\hline Dalit & 33 & 15 \\
\hline Janajati & 58 & 26.4 \\
\hline \multicolumn{3}{|l|}{ Type of family } \\
\hline Nuclear family & 98 & 44.5 \\
\hline Joint family & 122 & 55.5 \\
\hline \multicolumn{3}{|l|}{ Education Level } \\
\hline No education & 17 & 7.7 \\
\hline Primary & 37 & 16.8 \\
\hline Some secondary & 52 & 23.6 \\
\hline SLC or above & 114 & 51.8 \\
\hline \multicolumn{3}{|l|}{ Occupation } \\
\hline House maker & 107 & 48.6 \\
\hline Labour & 9 & 4.1 \\
\hline Agriculture & 52 & 23.6 \\
\hline service holder & 35 & 15.9 \\
\hline Business & 17 & 7.7 \\
\hline \multicolumn{3}{|c|}{ Income of family( Rs/month) } \\
\hline $7000-14000$ & 15 & 6.8 \\
\hline $14001-21000$ & 48 & 21.8 \\
\hline $21001-28000$ & 46 & 20.9 \\
\hline$\geq 28001$ & 111 & 50.5 \\
\hline \multicolumn{3}{|c|}{ Mean $\pm \mathrm{SD}=3.15 \pm 0.989$} \\
\hline \multicolumn{3}{|l|}{ Number of Children } \\
\hline None & 28 & 12.7 \\
\hline 1 & 55 & 25 \\
\hline 2 & 71 & 32 \\
\hline
\end{tabular}




\begin{tabular}{lll}
\hline$\geq 3$ & 66 & 30 \\
$\quad$ Mean $\pm \mathrm{SD}=2.80 \pm 1.011$ & & \\
$\begin{array}{l}\text { Heard about } \\
\text { preconception care }\end{array}$ & 129 & 58.6 \\
$\quad$ Yes & 91 & 41.4 \\
$\quad$ No & & \\
$\quad$ If yes & 45 & 20.5 \\
Source of information & 48 & 21.8 \\
$\quad$ Radio/ television & 12 & 5.5 \\
Health worker & 29 & 13.2 \\
$\quad$ Friends/family & & \\
Newspaper/books & &
\end{tabular}

Source: Field survey 2016

Table 1 reveals that, more than half $(56.4 \%)$ of the respondents were in the age group of more than 30 years, majority $(85.5 \%)$ of the respondents belonged to Hindu by religion, less than half $(47.3 \%)$ of the respondents were Brahmin, more than half $(55.5 \%)$ of the respondents were residing with joint family. With regard to educational level more than half $(51.8 \%)$ of the respondents passed SLC or above, with regard to occupational status of respondents less than half $(48.6 \%)$ of the respondents were housemaker, with regard to income of the family (Rs/month) about half $(50.5 \%)$ of the respondents income ranged for $>28001$. About one third (32\%) of the respondents had 2 children, more than half $(58.6 \%)$ of the respondents heard about the preconception care and the most common source of information were health worker which was less than one fourth $(21.8 \%)$ of the respondents.

Table 2

\begin{tabular}{lcc} 
Respondent's Classified According to Level of Knowledge on Preconception Care $(n=220)$ \\
\hline Level of knowledge & Frequency & Percent \\
\hline Poor $(<40)$ & 44 & 20.0 \\
Average $(40-61)$ & 142 & 64.5 \\
Good $(>61)$ & 34 & 15.5 \\
Total & 220 & 100 \\
\hline
\end{tabular}

Note: Cut off score was set as per (mean $\pm \mathrm{SD})$

Source: Field Survey 2016

Table 2 reveals that about $(20 \%)$ of respondents possessed poor knowledge, $(64.5 \%)$ of the respondents possessed average level of knowledge, $(15.5 \%)$ had good level of knowledge.

Similarly, table 3 reveals that there was statistically significant association of level of knowledge on preconception care with education $(p=0.000)$, number of children $(p=0.049)$, heard about preconception care $(\mathrm{p}=0.000)$, source of information $(\mathrm{p}=0.000)$ whereas there 
was no statistically significant association of level of knowled ge with age, religion, ethnicity, type of family, occupation and income $(\mathrm{p}>0.05)$.

Table 3

Association Between Knowledge and Selected Background Characteristics $(n=220)$

\begin{tabular}{|c|c|c|c|c|c|}
\hline \multirow[t]{2}{*}{ Variables } & \multirow[b]{2}{*}{ Poor } & \multicolumn{2}{|l|}{$\begin{array}{l}\text { Knowledge } \\
\text { level }(\%)\end{array}$} & \multirow[t]{2}{*}{$\begin{array}{l}\text { Chi square } \\
\text { value }\end{array}$} & \multirow[t]{2}{*}{ p- value } \\
\hline & & Average & Good & & \\
\hline \multicolumn{6}{|l|}{ Education } \\
\hline No education & $10(58.8)$ & $6(35.3)$ & $1(5.9)$ & 42.632 & 0.000 \\
\hline Primary & $16(43.2)$ & $16(43.2)$ & $5(13.5)$ & & \\
\hline Some secondary & $8(15.4)$ & $40(76.9)$ & $4(7.7)$ & & \\
\hline SLC or above & $10(8.8)$ & $80(70.2)$ & $24(21.1)$ & & \\
\hline \multicolumn{6}{|l|}{ Number of children } \\
\hline No child & $10(35.7)$ & $13(46.4)$ & $5(17.9)$ & 12.670 & 0.049 \\
\hline 1 child & $9(16.4)$ & $38(69.1)$ & $8(14.5)$ & & \\
\hline 2 child & $8(11.3)$ & $48(67.6)$ & $15(21.1)$ & & \\
\hline 3 and above & $17(25.8)$ & $43(65.2)$ & $6(9.1)$ & & \\
\hline \multicolumn{6}{|l|}{$\begin{array}{l}\text { Knowledge about } \\
\text { preconception care }\end{array}$} \\
\hline No & $35(38.5)$ & $47(51.6)$ & $9(9.9)$ & & \\
\hline Yes & $9(7)$ & $95(73.6)$ & $25(19.4)$ & 33.556 & 0.000 \\
\hline \multicolumn{6}{|l|}{$\begin{array}{l}\text { Source of } \\
\text { information }\end{array}$} \\
\hline Radio/television & $5(11.6)$ & $30(69.8)$ & $8(18.6)$ & 41.183 & 0.000 \\
\hline Health worker & $3(6.4)$ & $39(83)$ & $5(10.6)$ & & \\
\hline Friends/Family & 0 & $8(66.7)$ & $4(33.3)$ & & \\
\hline News paper/book & $1(3.7)$ & $18(66.7)$ & $8(29.6)$ & & \\
\hline
\end{tabular}

Source: Field survey 2016

\section{Discussion}

In present study among 220 respondents, more than half $(56.4 \%)$ of the respondents were from the age group of $>30$ years. The result of the study was supported by quantitative study conducted at Osun State, which reveals that age range of respondents was 20-59 years. Most respondents $(44.8 \%)$ were within the age range of $30-39$ years. Present study revealed that majority $(85.5 \%)$ of the respondents was from Hindu by religion and rest $14.5 \%$ were of other religion. Most of the respondents were Brahmin (47.3\%) by caste. More than half $(55.5 \%)$ of the respondents belonged to joint family. With regard to educational status, more than half $(51.8 \%)$ of the respondents belonged to SLC graduates and 7 percent of respondents were deprived from education. Almost half $(48.2 \%)$ of the respondents were unemployed and worked as house wives. With regard to income of the family (NRS/month) half $(50.5 \%)$ of the respondents income was above 28000 rupees. About one third (32\%) of 
the respondents had 2 children. This present study found that (15.5\%) of the respondents had the adequate knowledge of preconception care, two third $(64.5 \%)$ of the respondents had moderate knowledge and (20\%) of respondents had inadequate knowledge regarding the preconception care. This findings is in the line with previously study conducted at Birgunj by Thakuri \& Singh (2017).

In present study regarding the knowledge of preconception 69.5 percent expressed that correct answered that preconception care is the care provided to couple before conception.More than one third (35.4\%) of respondentsexpressed health promotion as the component of preconception care. 50.5 percent of the respondentsmentioned the correct answer that preconception care should be focused for both married and unmarried people. Most $(97.3 \%)$ of respondentsprovided the correct answer that preconception care is important to future offspring which is consistent to the finding of a study conducted at Dang by Gautam (2016). The study shows that55.9 percent of respondents were aware of preconception care, most of $(90.30 \%)$ of the respondents mentioned promoting health as the components of preconception care.

The study further reveals that third quarter $(75.9 \%)$ of the respondents provided the correct answer that preconception counselling is the counselling given to women well before planning pregnancy. More than one third (37.6\%) of respondents expressed family planning as a component of preconception counselling. This finding is contradictory with the finding of the study conducted at Oklahoma by Pramsgam (2010), which showed that only 12.0 percent of Oklahoma women received advice or counseling to prepare for becoming pregnant.

In this Present study more than one third (37.3\%) of respondentsmentioned barrier to preconceptioncare was lack of awareness and one fourth $(25 \%)$ of respondents mentioned aslimited access to health service. The finding is similar to the study conducted at MankatobyPaulsen, et.al(2017) on preconception health knowledge among undergraduate women which shows that the greatest barrier was lack of knowledge which support the present study. More than one third (36.1\%) of the respondents expressed that low birth weight as a effects of alcohol in pregnancy, 28.1 percent followed by as miscarriage. This study was supported by the study conducted in River state, Nigeria by Ordinioha, \& Birsibe (2015) which shows that about half (51.5\%) of the respondents in this study knew the harmful effects of alcohol on the fetus. 
Similarly, (40.5\%) of the respondents mentioned correct answer that women should start preparing for pregnancy 3 month before conception. More than one third $(38.6 \%)$ of the respondents provided the correct answer that folic acid should be taken 3 month prior to conception. Similar findings were observed in the study conducted at Dang by Gautam, (2016) which revealed that awareness for preparing for pregnancy was high $(55.07 \%)$ conception but contradictory with the findings that only 11.46 percent had awareness about folic acid.

There was statistically significant association of level of knowledge of preconception care with education (0.000), occupation (0.001), number of children (0.007), heard about preconception care (0.000), source of information ( $\mathrm{p}=0.000)$. Similarly, a significant association was found between respondents educational level and knowledge of preconception care which was similar with the study done at Osun State, Nigeria by Olowokere, et al. (2015).

\section{Conclusion}

The study findings concluded that 20 percent of the respondents in the study had poor level of knowledge, more than two third of the respondents 64.5 percent in the study had average level of knowledge and 15.5 percent of the respondents of the study had good knowledge about the preconception care. There was statistically significant association between level of knowledge on preconception care with education, number of children, heard about preconception care and source of information .

\section{Acknowledge ment}

I would like to extend overwhelming gratitude to Novel Academy for providing me an opportunity to conduct this research. My heartfelt expression of sincere gratitude and appreciation to my research supervisor Ms. Srijana Gautam, Ms. Pushpa Timilsina, Professor Dr. Vikash Kumar K.C, for their precious guidance, support, valuable suggestions. I would like to express thanks to Pokhara Metropolitan City-32 for granting me the permission to carry out the research as well as I would like to thank all the respondents of my study for giving me valuable information for my research study.

\section{References}

Chamberlain, G. (2011). Preconception Care. Retrived from https://www.ncbi.nlm.nih.gov/pmc/articles/PMC3796961. 
Dean, S.V., Lassi, Z.S., Imam, A.M., \& Bhutta, Z.A. (2014). Preconception Care closing the gap in the continuum of care to accelerate improvements in maternal, newborn and child health. Reproductive Health journal, 11(3).

Dhakal, K.(2013).Impact Of Educational Intervention on Awareness Regarding Preconception Care Among Bachelor level students. Journal of Society of Surgeons of Nepal, 16(2),34-39.

Frey, K.A.(2010). Preconception care by the non obstetrical provider. Mayo Clinic Proceedings, 77(5), 469-47.

Gautam, P.,\& Dhakal, P., (2016). Knowledge on Preconception Care among Reproductive age Women. Saudi Journal of Medical and Pharmaceutical Sciences, 2 (1), 2.

Kasim, R., Draman, N., Kadir, A., \& Muhamad, R. (2016).Knowledge, Attitudes and Practice of Preconception Care among Women Attending Maternal Health Clinic in Kelantan. Education in Medicine Journal, 8(4). 60.

Kent, H., Johnson, k., Curtis, M.,Richardson,J.H. (2006). Proceedings of the Preconception Health and Health Care Clinical. 3-4.

Moos, M.K., Dunlop, A.L.,Jack, B.W.(2009). Healthier women, healthier reproductive outcomes: recommendations for the routine care of all women of reproductive age. American Journal of Obstetrics \& Gynecology 2, 199(6), 280-289.

Ojukwu, O., Patel, D., Stephenson, J., Howden, B., Shawe, J. (2016). General practitioners' knowledge, attitudes and views of providing preconception care. Upsala Journal of Medical Sciences, 121(4), 256-263.

Olowokere, A.E., Komolafe, A., Owofadeju, C., (2017). Awareness, Knowled ge and Uptake of Preconception Care among Women in Ife Central Local Government Area of OsunState, Nigeria. Journal of Community Medicine and Primary Health Care, 3(7), 481-488

Ordinioha, B., \& Brisibe, S.,(2015). Alcohol consumption among pregnant women attending the ante-natal clinic of a tertiary hospital in South-South Nigeria. Nigerian Journal of clinical practice,18(1), 13-7

Paulsen, A.M., (2017). Preconception Health Knowledge among Undergraduate Women. All Theses, Dissertations, and Other Capstone Projects. 677.

PRAMS Working Group. (2010). Preconception Care Among Oklahoma Women. Oklahoma State Department of Health, 12(1). 2-6.

Thakuri, S.R., Singh, B., (2017). Knowledge on preconception care : an issue among reproductive age women attending Gynecological/Obstetric OPD of National Medical College. International journal of advance research, 5(2). 2311-2314.

Tuitui, R. (2016). Manual of Midwifery I. Antepartum and Gynaecological Nursing: Bhotanity, Kathmandu, 33. 
Van der Zee, B., Temel, S., Denktas, S., \& Steegers, E. (2011). Preconception care: an essential preventive strategy to improve children's and women's health. Journal Public Health Policy, 32(3), 1.

World Health Organization, (2013). Meeting to develop a global consensus on preconception care to reduce maternal and child hood mortality and morbidity. Geneva.

World Health Organization (2011). Perinatal mortality. Retrived from http://apps.who.int/iris/bitstream/handle/10665/43444/9241563206_eng.pdf;jses sionid $=63 \mathrm{E} 752 \mathrm{D} 751 \mathrm{~B} 2 \mathrm{~B} 8 \mathrm{AA} 2 \mathrm{C} 93 \mathrm{AAD} 9131 \mathrm{BE} 5 \mathrm{ED}$ ? sequence $=1$ 